\title{
Material Cost Advantage and Development of Small Printing Industry: Based on the Case of Xinhua Phenomenon
}

\author{
Lei $\mathrm{Wu}^{1,{ }^{*}}$ and Fengtian Zheng ${ }^{2}$ \\ ${ }^{1}$ School of Economics \& Business Administration, Central China Normal University, Wuhan, China \\ ${ }^{2}$ School of Agricultural Economics and Rural Development, Renmin University of China, Beijing, China
}

\begin{abstract}
Based on the survey of small printing industry in Beijing, Xi' an and Zhengzhou, this paper analyses the development of Xinhua Phenomenon as one case of Rural Migration Entrepreneurship and find that group culture is an important factor to promote the development of Xinhua Phenomenon. Through the econometric analysis, the research finds that Xinhua printing group offers better services than non-Xinhua group to gain the material cost advantage and promote the development of Xinhua Phenomenon.
\end{abstract}

\section{Introduction}

The reason why rural migration entrepreneurship was able to form and grow is that it must have business and cost advantages. Look at the Xinhua phenomenon in printing industry, for example, Xinhua population has occupied half market of the printing industry and continue to attract more people to enter printing industry. Xinhua population, as a whole, is likely to have a common operating advantage, which allows them to take the initiative in competition with non-Xinhua people. When we carried out investigation on print and copy shops opened by non-Xinhua people, they think the biggest advantage of Xinhua people is "clannishness" and "low cost". They reflect, the toners used by Xinhua people are "generally recycled" and the equipment and material suppliers are mostly Xinhua people, so in the supply channels," Xinhua people will certainly take care of their fellows." As can be seen from the survey interview, Xinhua people run print and copy shops, and in the course of operation, it seems that there is an invisible force allowing them to maintain a cost advantage, however, this power can not be explained by some of the traditional factors in entrepreneurship - such as capital operation, financial support, etc.. What exactly is the unique factor that maintains the material cost advantage of rural migration entrepreneurship?

Because Xinhua people as a whole have a common advantage in printing industry, culture is likely to be an important factor to maintain the entrepreneurship operating advantage. In the domestic and foreign research on entrepreneurship, more and more scholars gradually go beyond the traditional explain model on entrepreneurship factors, and begin to focus on the role of culture in entrepreneurship. Weber (1904) first highlighted the impact of culture on entrepreneurship, and suggested that Protestant ethic can produce incentives which make people engage in entrepreneurial activity. [1] In fact, many groups worldwide are considered very good at entrepreneurial activities, such as Jiangsu and Zhejiang region of China, this is likely to comply with inference of Weber (1904), it is the geographical or group culture that promotes the development of certain group entrepreneurial activities. [1] In addition, for the different groups good at entrepreneurial activity, the reasons are different. Some groups may have a comparative advantage in certain entrepreneurship industries, while some other groups may choose to entrepreneurship because they have no access to other jobs, such as the Jews in medieval Europe, as well as many migrant workers in China. Due to the variety of physical and mental barriers existed in cities, in order to survive in the city, they can only carry out entrepreneurship activities in some industries which city people do not want to engage in. As can be seen, some of the groups are good at entrepreneurial activity, one possible explanation is that they are able to learn relevant entrepreneurship skills and experience from family or community groups (Bertrand and Schoar, 2006), [2] another possible explanation is that entrepreneurial culture can instill trust norms and consensus to community groups in people's upbringing and education process, which will help them to carry out entrepreneurial activities within the group. Thus, the culture here become a potential promoting mechanism which make members within the group reach a high level of confidence balance (Guiso et al, 2006). [3]

Therefore, in the operation of printing shops, Xinhua people, on the one hand, have relatively unique regional entrepreneurial and operation culture, which is likely to make them build a good transaction relationship with customers; on the other hand, the cultural short-

*Corresponding author: w1411@,126.com 
circuiting effect generated between fellows of Xinhua entrepreneurs and Xinhua equipment suppliers, is likely to reduce more material and spiritual costs for Xinhua entrepreneurs than non-Xinhua entrepreneurs, making the Xinhua people occupy a dominant position in printing industry. Therefore, this paper begins next with the cultural perspective, analysing "cultural well-being" obtained by Xinhua printing entrepreneurs in their operation.

\section{Analytical framework}

Just as our study on Xinhua and other non-Xinhua groups, when carrying out economic activities, different groups have different behaviours, this difference will also lead to different results in economic activities. Particularly, different business groups have different operation modes. For printing industry, it mainly reflected in the way of dealing with customers and suppliers. The culture of entrepreneurship groups has become a unique label attached to the entire population. Therefore, when interpreting the unique operating method of certain entrepreneurship group, the group culture here can be classified as shared cultural identity category. Becker (1996) pointed out in the meaning of culture that individuals' cultural control force is significantly lower than other social capital, they can not change their race, ethnicity, and family history, moreover, the countries and regions where they belong is also very difficult to change.[4] Because culture is difficult to change and it has a lower depreciation rate, thus, culture can be seen as a gift to a individual's whole life. Therefore, culture here can be considered as a collection of shared values, beliefs and norms of groups or communities.

In economic transactions between owners and customers, an important indicator is discount. Although for the print and copy shops in college, one-page print or copy costs about 1 or 2 dimes, just seems to have no room for discount, but the print quantity of some teachers and students is big, so a large quantity favourably. Many print and copy shops will give discount only when the print reaches a certain quantity or amount. Therefore, on the questionnaire, we asked "how much the average customers cost to enjoy discount". Another indicator is the margin of discount, such as" how much discount will they offer". Thus, these favourable issues are likely to be the operating difference between Xinhua and non-Xinhua groups.

In addition to the discount, some "soft factors" could also affect operating performance, and different group culture will be reflected on these factors. For example, will they greet customers with a smile? Will they provide some refreshments, snacks, drinks or tea? and so on. These soft factors could deepen the customer's first impression, and owners can be closer to customers through these soft factors, through which they can establish a long-term and stable transaction relationship and solicit more "repeat customers." Thus, these soft factors are also crucial for print and copy shops, and the performance of different groups in the soft factors are also likely to vary.

\section{Data and variables}

The data used in this paper are from the sample survey in small printing industry owners in Beijing, Xi'an and Zhengzhou. Specific variables setting and measurement methods as shown below.

First look at the descriptive statistics about transaction indicators of owners and customers, as shown in Table 1.

Table 1. The economic transaction indicators of shop owners and customers.

\begin{tabular}{|c|c|c|c|c|}
\hline Variables & Assignment or description & $\begin{array}{l}\text { Overall } \\
\text { sample }\end{array}$ & $\begin{array}{l}\text { Xinhua } \\
\text { sample }\end{array}$ & $\begin{array}{l}\text { Non- } \\
\text { xinhua } \\
\text { sample }\end{array}$ \\
\hline Gender & $1=$ male, $0=$ female & 0.740 & 0.762 & 0.730 \\
\hline Age & Unit:years old & 33.76 & 33.65 & 33.69 \\
\hline Years of education & Unit:year & 10.07 & 9.033 & 10.91 \\
\hline Marital status & $1=$ Married, $0=$ Unmarried & 0.253 & 0.208 & 0.270 \\
\hline nationality & $1=$ Han, $0=$ Minority & 0.965 & 0.951 & 0.983 \\
\hline Political affiliation & $\begin{array}{l}1=\text { Member of Communist Party, } 2=\text { Member of } \\
\text { Democratic Party, } \\
3=\text { League member, } 4=\text { masses }\end{array}$ & 3.613 & 3.873 & 3.475 \\
\hline Purchase insurance & $1=$ Yes,, $0=$ No & 0.495 & 0.342 & 0.602 \\
\hline $\begin{array}{l}\text { Logarithm of } \\
\text { consumption for } \\
\text { discount }\end{array}$ & $\begin{array}{l}\text { Logarithmof required minimum consumption(unit: } \\
\text { yuan) for discount }\end{array}$ & 3.880 & 4.452 & 3.509 \\
\hline $\begin{array}{l}\text { Logarithm of } \\
\text { margin of } \\
\text { preference }\end{array}$ & $\begin{array}{l}\text { Logarithm of the maximum } \\
\text { margin of preference(unit:\%) }\end{array}$ & 1.873 & 1.927 & 1.830 \\
\hline $\begin{array}{l}\text { Home delivery serv } \\
\text { ice }\end{array}$ & $1=$ yes, $0=$ no & 0.588 & 0.783 & 0.456 \\
\hline $\begin{array}{l}\text { Greet customers } \\
\text { with a smile }\end{array}$ & $1=$ often or always, $0=$ generally,rarely or never & 0.563 & 0.442 & 0.651 \\
\hline Provide food & $1=$ often or always, $0=$ generally,rarely or never & 0.0275 & 0.0263 & 0.0283 \\
\hline $\begin{array}{l}\text { Provide water or } \\
\text { drink }\end{array}$ & $1=$ often or always, $0=$ generally, rarely or never & 0.0833 & 0.107 & 0.0667 \\
\hline $\begin{array}{l}\text { Logarithm of open } \\
\text { period }\end{array}$ & $\begin{array}{l}\text { Logarithm of the period that the print and } \\
\text { copy shop has been opened(unit: month) }\end{array}$ & 3.377 & 3.522 & 3.276 \\
\hline $\begin{array}{l}\text { Have } \\
\text { business license }\end{array}$ & $1=$ yes, $0=$ no & 0.813 & 0.829 & 0.802 \\
\hline
\end{tabular}

As can be seen from Table 1, in the overall sample, the average logarithm of consumption for discount is 3.88 , while in the Xinhua sample, it is 4.452 , in the nonXinhua sample it is 3.509 , the value is greater in Xinhua sample than the non-Xinhua sample, indicating that in Xinhua print and copy shops, customers need to spend more money in order to enjoy the discount. From the preferential margin, in the overall sample, the average logarithm is 1.873 , while in the Xinhua and non-Xinhua samples it is 1.927 and 1.830 , respectively, indicating that in terms of the discount, it is greater in Xinhua print and copy shops. For home delivery service, $58.8 \%$ of respondents in overall sample confirmed that they provide this service, while in the Xinhua and nonXinhua samples it is $78.3 \%$ and $45.6 \%$, respectively. Taking a holistic look of the results, Xinhua shop owners prefer to provide this service. As can be seen from the statistical results of three "soft factors", in the overall sample, owners who "often" or "always" greet customers account for $56.3 \%$ of the respondents, while in the Xinhua and non-Xinhua samples it is $44.2 \%$ and $65.1 \%$ respectively. That is, non-Xinhua owners are more 
inclined to greet customers with a smile. As for providing food or snacks, regardless of the overall sample, Xinhua sample or non-Xinhua sample, those who can "often" or "always" provide food or snacks are less, the proportion is $2.75 \%, 2.63 \%$ and $2.83 \%$, respectively. It can be seen that this proportion of nonXinhua owners is slightly larger than the Xinhua owners. As for providing water or drink, regardless of the overall sample, Xinhua sample or non-Xinhua sample, those who can "often" or "always" provide water or drink are less, the proportion is $8.33 \%, 10.7 \%$ and $6.67 \%$, respectively. It can be seen that this proportion of Xinhua owners is larger than the non-Xinhua owners. Table 6-1 also gives other information about print and copy shops, judging from the run length of copy and print shops, the average logarithm of length in overall sample is 3.377, while in the Xinhua and non-Xinhua samples, it is 3.522 and 3.276, respectively. The period that Xinhua people run print and copy shops is longer than non-Xinhua people. Judging from whether shop has a business license, the proportion of having business licenses in the overall sample is $81.3 \%$, while in the Xinhua and non-Xinhua samples it is $82.9 \%$ and $80.2 \%$, respectively. The owing rate of business license in the three samples are all high, but it is larger in Xinhua sample than non-Xinhua sample.

\section{Models and methods}

In the level of economic transactions between print and copy shop owners and customers, we mainly analyse the impact of group cultural identity on business operations, namely whether Xinhua shop owners can have more advantages in some business indicators than non-Xinhua owners. Therefore, the explanatory variable here is whether the print and copy shop owners are Xinhua people, "Yes" is marked as 1 and "No" is marked as 0 . If explained variables are continuous, such as logarithm of consumption for discount and logarithm of margin of preference, then we use ordinary least squares estimation method for analysis; if explained variables are binary discrete, such as whether have home delivery service, whether greet with a smile, provide food, water or drink, then we use Probit Model for analysis.

\section{Results}

Firstly, in economic transactions with customers, we analyse the difference between Xinhua and non-Xinhua owners in the minimum consumption for discount, preferential margin and home delivery service, the specific results of the analysis are shown in Table 2.

In Table 2, explained variable of the model (1) and (2) is logarithm of consumption for discount, namely the logarithm of minimum consumption required for discount, using ordinary least squares estimation method for analysis; explained variable of the model (3) and (4) is logarithm of margin of preference, using ordinary least squares estimation method for analysis; explained variable of model (5) and (6) is whether have the home delivery services, using the probit model for analysis; In addition, the model (2), (4) and (6) also put some information variables such as logarithm of open period and whether have business license.

Table 2. Difference between Xinhua and non-Xinhua owners in the minimum consumption for discount, preferential margin and home delivery service.

\begin{tabular}{|c|c|c|c|c|c|c|}
\hline Variables & $\begin{array}{c}\text { (1) } \\
\text { Logarithm of } \\
\text { consumption } \\
\text { for discount }\end{array}$ & $\begin{array}{l}\text { (2) } \\
\text { Logarithm of } \\
\text { consumption } \\
\text { for discount }\end{array}$ & $\begin{array}{c}\text { (3) } \\
\text { Logarithm } \\
\text { of margin of } \\
\text { preference }\end{array}$ & $\begin{array}{c}\text { (4) } \\
\text { Logarithm } \\
\text { of margin of } \\
\text { preference }\end{array}$ & $\begin{array}{c}\text { (5) } \\
\text { Home delivery } \\
\text { service }\end{array}$ & $\begin{array}{c}\text { (6) } \\
\text { Home } \\
\text { delivery } \\
\text { service }\end{array}$ \\
\hline \multirow[t]{2}{*}{ Xinhua people } & $0.701^{* *}$ & $0.698^{* *}$ & -0.129 & -0.125 & $0.701^{* *}$ & $0.731 * *$ \\
\hline & $(0.296)$ & $(0.296)$ & $(0.177)$ & $(0.175)$ & $(0.333)$ & $(0.343)$ \\
\hline \multirow[t]{2}{*}{ Male } & -0.177 & -0.171 & 0.155 & 0.180 & 0.379 & 0.419 \\
\hline & $(0.280)$ & $(0.301)$ & $(0.209)$ & $(0.216)$ & $(0.338)$ & $(0.331)$ \\
\hline \multirow[t]{2}{*}{ Age } & 0.00168 & 0.00128 & $-0.0237^{* *}$ & $-0.0219^{* *}$ & $-0.0450^{* * *}$ & $-0.0435 * *$ \\
\hline & $(0.0168)$ & $(0.0169)$ & $(0.0105)$ & $(0.00974)$ & $(0.0171)$ & $(0.0191)$ \\
\hline \multirow[t]{2}{*}{$\begin{array}{c}\text { Years of } \\
\text { education }\end{array}$} & $-0.0890^{*}$ & $-0.0889^{*}$ & -0.0310 & -0.0330 & $-0.123 * *$ & $-0.142^{* *}$ \\
\hline & $(0.0532)$ & $(0.0535)$ & $(0.0222)$ & $(0.0234)$ & $(0.0572)$ & $(0.0597)$ \\
\hline \multirow[t]{2}{*}{ Unmarried } & -0.227 & -0.222 & -0.0888 & -0.133 & $-0.741^{*}$ & $-0.773 *$ \\
\hline & $(0.280)$ & $(0.285)$ & $(0.225)$ & $(0.227)$ & $(0.388)$ & $(0.398)$ \\
\hline \multirow{2}{*}{$\begin{array}{c}\text { League membe } \\
\mathrm{r}\end{array}$} & 0.493 & 0.497 & -0.165 & -0.0992 & 0.689 & 0.753 \\
\hline & $(0.680)$ & $(0.680)$ & $(0.486)$ & $(0.456)$ & $(0.637)$ & \\
\hline Masses & $\begin{array}{c}0.623 \\
(0.650)\end{array}$ & $\begin{array}{c}0.616 \\
(0.670)\end{array}$ & $\begin{array}{c}0.458 \\
(0.440)\end{array}$ & $\begin{array}{c}0.558 \\
(0.415)\end{array}$ & $\begin{array}{c}0.849 \\
(0.646)\end{array}$ & $\begin{array}{c}0.893 \\
(0.655)\end{array}$ \\
\hline \multirow[t]{2}{*}{$\begin{array}{l}\text { Purchase } \\
\text { insurance }\end{array}$} & 0.365 & 0.357 & 0.000892 & 0.106 & 0.267 & 0.329 \\
\hline & $(0.263)$ & $(0.263)$ & $(0.185)$ & $(0.181)$ & $(0.312)$ & $(0.310)$ \\
\hline \multirow[t]{2}{*}{$\begin{array}{l}\text { Logarithm of } \\
\text { open period }\end{array}$} & & -0.0113 & & 0.0783 & & 0.170 \\
\hline & & $(0.114)$ & & $(0.102)$ & & $(0.128)$ \\
\hline \multirow[t]{2}{*}{$\begin{array}{c}\text { Have } \\
\text { business license }\end{array}$} & & 0.0662 & & $-0.480^{* *}$ & & $-0.601 *$ \\
\hline & & $(0.314)$ & & $(0.236)$ & & $(0.355)$ \\
\hline \multirow[t]{2}{*}{ Constant term } & $3.893^{* * *}$ & $3.896 * * *$ & $2.602 * * *$ & $2.514^{* * *}$ & 1.800 & 1.788 \\
\hline & $(1.271)$ & $(1.324)$ & $(0.688)$ & $(0.771)$ & (1.269) & (1.357) \\
\hline Sample size & 104 & 104 & 108 & 108 & 101 & 100 \\
\hline
\end{tabular}

Robust standard errors in parentheses $* * * \mathrm{p}<0.01, * * \mathrm{p}<0.05, * \mathrm{p}<0.1$

As can be seen from model (1) and (2) in Table 2, the coefficient that owners are Xinhua people is positive and the impact on logarithm of consumption for discount is significant at the $95 \%$ level, indicating the minimum consumption for discount required by Xinhua owners is higher than non-Xinhua owners, and the two have significant difference, Xinhua owners prefer "large favourably", only when reach certain consumption, can customers enjoy discount. While non-Xinhua owners do not set such high level, they are easier to give customers discount. To some extent, this reflects the Xinhua people have dominated printing industry, in order to compete with them, non-Xinhua people have to make concession by requiring low minimum consumption.

As can be seen from model (3) and (4) in Table 2, whether the owners are Xinhua people doesn't have significant influence on logarithm of margin of preference, indicating that there is on significant difference in margin of preference. Possible reason is that the size of the print and copy shops in universities is generally small, the price tends to be the same low level, the situation is close to perfect competition, the profit from a single customer's consumption is relatively small, which may lead to the less difference in margin of preference.

As can be seen from model (5) and (6) in Table 2, the 
coefficient that owners are Xinhua people is positive and the impact on home delivery service is significant at the 95\% level, indicating that compared with non-Xinhua owners, the Xinhua owners prefer to provide home delivery service. In college printing market, providing home delivery service has benefits for both the teachers and students as well as print and copy shop itself. For some university teachers or research teams, their print and copy quantity is generally large, so they welcome home delivery service. If the owner can provide this service, then his shop will form a good service reputation among teachers and students, there will be more research teams who need large print and copy quantity contacting with this shop. Thus, the Xinhua owners prefer to provide home delivery service, although they pay some cost, but be able to establish a stable consumption relation and better service reputation, making the Xinhua print and copy shops occupy the service advantage in the long run.

In services of print and copy shops, the "soft factors" can also play the role of "service catalyst", it is significant for attracting customers and promoting business, next, we will analyse the different performance of Xinhua and non-Xinhua owners in "soft factors" and specific results as shown in Table 3.

Table 3. The different performance of Xinhua and non-Xinhua owners in "soft factors".

\begin{tabular}{|c|c|c|c|c|c|c|}
\hline Variables & $\begin{array}{c}\text { (1) } \\
\text { Greet } \\
\text { customers } \\
\text { with a smile }\end{array}$ & $\begin{array}{c}\text { (2) } \\
\text { Greet } \\
\text { customers } \\
\text { with a smile }\end{array}$ & $\begin{array}{c}\text { (3) } \\
\text { Provide food }\end{array}$ & $\begin{array}{c}\text { (4) } \\
\text { Provide food }\end{array}$ & $\begin{array}{c}\text { (5) } \\
\text { Provide water } \\
\text { and drink }\end{array}$ & $\begin{array}{c}\text { (6) } \\
\text { Provide wa } \\
\text { and drink }\end{array}$ \\
\hline Xinhua people & $\begin{array}{c}-0.366 \\
(0.230)\end{array}$ & $\begin{array}{c}-0.376 \\
(0.237)\end{array}$ & $\begin{array}{c}0.223 \\
(0.509)\end{array}$ & $\begin{array}{c}0.305 \\
(0.431)\end{array}$ & $\begin{array}{c}0.503 \\
(0.314)\end{array}$ & $\begin{array}{c}0.644^{* * *} \\
(0.323)\end{array}$ \\
\hline Male & $\begin{array}{c}-0.151 \\
(0.245)\end{array}$ & $\begin{array}{l}-0.122 \\
(0.255)\end{array}$ & $\begin{array}{l}-0.321 \\
(0.378)\end{array}$ & $\begin{array}{c}-0.657^{* * *} \\
(0.308)\end{array}$ & $\begin{array}{c}-0.385 \\
(0.288)\end{array}$ & $\begin{array}{c}-0.357 \\
(0.314)\end{array}$ \\
\hline Age & $\begin{array}{c}0.000933 \\
(0.0133)\end{array}$ & $\begin{array}{c}-0.000726 \\
(0.0140)\end{array}$ & $\begin{array}{c}-0.00467 \\
(0.0134)\end{array}$ & $\begin{array}{l}-0.0141 \\
(0.0155)\end{array}$ & $\begin{array}{l}-0.0344 \\
(0.0221)\end{array}$ & $\begin{array}{c}-0.0364 \\
(0.0240)\end{array}$ \\
\hline $\begin{array}{l}\text { Years of } \\
\text { education }\end{array}$ & $0.0921^{* *}$ & $0.0895 * *$ & 0.0633 & 0.0497 & 0.0505 & 0.0351 \\
\hline Unmarried & $\begin{array}{c}0.226 \\
(0.267) \\
-0.562\end{array}$ & $\begin{array}{c}0.248 \\
(0.273) \\
-0.519\end{array}$ & $\begin{array}{l}-0.0600 \\
(0.384)\end{array}$ & $\begin{array}{l}0.219 \\
(0.418)\end{array}$ & $\begin{array}{c}-0.170 \\
(0.469) \\
3.607 * * *\end{array}$ & $\begin{array}{c}-0.134 \\
(0.435) \\
3.204^{* * *}\end{array}$ \\
\hline League member & & & & & & \\
\hline Masses & $\begin{array}{l}(0.511) \\
-0.175 \\
(0.475)\end{array}$ & $\begin{array}{l}(0.531) \\
-0.178 \\
(0.474)\end{array}$ & $\begin{array}{c}-0.851^{* * *} \\
(0.421)\end{array}$ & $\begin{array}{c}-1.183^{* * *} \\
(0.522)\end{array}$ & $\begin{array}{c}(0.577) \\
4.372^{* * * *} \\
(0.477)\end{array}$ & $\begin{array}{c}(0.715) \\
4.092^{* * * *} \\
(0.436)\end{array}$ \\
\hline $\begin{array}{l}\text { Purchase } \\
\text { insurance }\end{array}$ & -0.0304 & 0.0328 & 0.205 & 0.220 & $0.840^{* *}$ & $0.846^{* *}$ \\
\hline $\begin{array}{l}\text { Logarithm of } \\
\text { open period }\end{array}$ & $(0.218)$ & $\begin{array}{c}(0.222) \\
0.151\end{array}$ & $(0.398)$ & $\begin{array}{c}(0.385) \\
-0.261\end{array}$ & $(0.332)$ & $\begin{array}{c}(0.356) \\
-0.313^{* *}\end{array}$ \\
\hline $\begin{array}{c}\text { Have } \\
\text { business license }\end{array}$ & & $\begin{array}{l}(0.106) \\
-0.517^{*}\end{array}$ & & $(0.252)$ & & $\begin{array}{c}(0.140) \\
0.446\end{array}$ \\
\hline & & $(0.293)$ & & & & $(0.504)$ \\
\hline Constant term & $\begin{array}{l}-0.331 \\
(0.864)\end{array}$ & $\begin{array}{l}-0.405 \\
(0.903)\end{array}$ & $\begin{array}{l}-1.801 \\
(1.420)\end{array}$ & $\begin{array}{l}0.0156 \\
(0.786)\end{array}$ & $\begin{array}{c}-5.515^{* * *} \\
(1.383)\end{array}$ & $\begin{array}{r}-4.474^{* * *} \\
(1.350)\end{array}$ \\
\hline Sample size & 163 & 162 & 138 & 116 & 160 & 160 \\
\hline
\end{tabular}

Robust standard errors in parentheses

${ }^{* * *} \mathrm{p}<0.01,{ }^{* *} \mathrm{p}<0.05,{ }^{*} \mathrm{p}<0.1$

In the model (1) and (2) of Table 3, the explained variable is whether the owner can "often" or "always" greet customers with a smile; in model (3) and (4) the explained variable is whether the owners can "often" or "always" provide customers with food or snacks; in model (5) and (6) the explained variable is whether the owners can "often" or "always" provide customers with water or drinks; thus The model (1) - (6) are analysed using the probit model; In addition, the model (2), (4) and (6) also put some information variables such as logarithm of open period and whether have business license.

As can be seen from Table 3, whether the owners are Xinhua people doesn't have significant influence on whether they can "often" or "always" greet customers with a smile and whether they could "often" or "always" provide customers with food or snacks, while the impact on whether the owners can "often" or "always" provide customers with water or beverages is statistical significant at the $95 \%$ level, and its coefficient is positive, indicating that the first two variables have no apparent relationship with where the owners come from, but in the third variable, the performance of Xinhua owners is better than non-Xinhua owners. The results show that, to some extent, Xinhua owners are more passionate to customers than the non-Xinhua owners, this will narrow the distance with customers, thereby laying the foundation for long-term and stable relationship of economic transactions. In the survey interviews we found that some shop owners said they would collect water for customers from the drinking machine if they were not busy, so the owner said, "Now we get to know a lot of acquaintances," "they have become repeat customers."

As can be seen from the above analysis, from a whole, the Xinhua owners have better performance in terms of customer service than non-Xinhua owners, especially in the "soft factors" they give a good impression on customers, which help to establish longterm stable economic transaction relationships with customers. Therefore, the group entrepreneurship culture represented by good service has played a crucial role in development and growth of Xinhua phenomenon in printing industry.

\section{Conclusions}

Based on group entrepreneurial culture, using survey data of college print and copy shops in Beijing, Xi'an and Zhengzhou three cities, this paper analysed the service differences in Xinhua and non-Xinhua owners' economic transaction with customers. The main conclusions of this paper can be summed up as follows:

Compared with non-Xinhua owners, the Xinhua owners prefer to provide home delivery service, although increase some cost, they are able to establish a stable consumption relationship and good service reputation, in the long run, it make the print and copy shops of Xinhua people take advantage in service; in addition, in services of print and copy shops, the "soft factors" can also play the role of "service catalyst", it is significant for attracting customers and promoting business, the empirical results show that, whether the owners are Xinhua people doesn't have significant relationship with whether they can "often" or "always" greet customers with a smile and whether they could "often" or "always" 
provide customers with food or snacks, while the possibility that Xinhua owners "often" or "always" provide customers with water or drink is greater than non-Xinhua owners, indicating that to some extent, Xinhua owners are more passionate to customers than the non-Xinhua owners, this will narrow the distance with customers, thereby laying the foundation for longterm and stable relationship of economic transactions. Therefore, the Xinhua owners have better performance in terms of customer service than non-Xinhua owners, especially in the "soft factors", they give a good impression on customers, which help to establish longterm stable economic transaction relationships with customers. Therefore, the group entrepreneurship culture represented by good service has played a crucial role in development and growth of Xinhua phenomenon in printing industry.

In conclusion, culture has been more and more concerned in the study of entrepreneurship. Conclusions of this paper show that, culture has played a crucial role for Xinhua group to gain the material cost advantage in printing industry which is a typical representative of rural migration entrepreneurship, and it is promoting the development and growth of Xinhua phenomenon in printing industry.

\section{Acknowledgement}

This paper is supported by MOE (Ministry of Education in China) Project of Humanities and Social Sciences (Project No.16YJCZH113).

\section{References}

1. Weber, M. (1904), (1930 English translation), The Protestant Ethic and the Spirit of Capitalism. New York: Scribner; London: Allen and Unwin.

2. Bertrand, M., and Schoar, A. (2006), The Role of Family in Family Firms, Journal of Economic Perspectives, Vol. 20, 73-96.

3. Guiso, L., Sapienza, P., and Zingales, L. (2006), Does Culture Affect. Economic Outcomes? The Journal of Economic Perspectives, Vol. 20, 23-48.

4. Becker, G. (1996), "Preferences and Values," in Becker Gary (ed.), Accounting for Taste, Harvard University Press: Cambridge. 